Milica B. Abramović*

Filološki fakultet

Univerzitet u Beogradu
УДК

821.111(73).09-31 Вонегат К

ДОИ

https://doi.org/10.18485/analiff.2016.28.2.9

\title{
METAFIKCIJA U PROZI KURTA VONEGATA
}

Metafikcija, ili fikcija o fikciji, je, po Patriši Vo, tekst fikcije koji je svestan sebe kao teksta fikcije, i koji skreće čitaocu pažnju na svoju fikcionalnost, odnosno na vezu između fikcije i realnosti. Ova vrsta fikcije postaje posebno popularna u postmodernizmu i karakteristična za većinu eksperimentalnih tekstova. Upoređivanjem načela metafikcije, kako je definišu Patriša Vo i Linda Hačon, sa elementima iste u romanima Kurta Vonegata, ovaj rad ima za cilj da prikaže na koji način Vonegat koristi metafikciju u svojoj prozi. Analiziranjem romana Breakfast of champions postaje očigledno da Vonegat izvrće metafikciju i dovodi je do apsurda. Apsolutna konfuzija koja nastaje u pokušaju da se odredi ko je zapravo Kurt Vonegat u ovom romanu (autor, narator, lik ili uljez) i Vonegatov prolazak kroz portal iz realnosti u fikciju (u kojoj ne može dugo da se zadrži niti da kontroliše svoje likove) ukazuje na to da Vonegat prevazilazi tehnike metafikcije i da ih namerno parodira.

Ključne reči: Kurt Vonnegut, Breakfast of Champions, SlaughterhouseFive, metafikcija, parodija

Kurta Vonegata (Kurt Vonnegut) je teško žanrovski kategorisati kao pisca naučne fantastike ili kao humoristu, zbog upotrebe pastiša i kombinacije raznih žanrova u njegovim delima. U jednom romanu prepoznaćemo elemente naučne fantastike, crne komedije, pa čak i pornografije, kao što je slučaj sa romanom Breakfast of Champions (1973). Ne znamo da li bi Vonegat svoja dela opisao kao postmodernistička, ali mi moramo upotrebiti baš tu etiketu zbog određenih osobina njegovih romana. Neki kritičari, kao što je Dejvid Kovart (David Cowart), smatraju da je Vonegat u stvari modernista, ili da se bar nalazi na granici između dva pravca. Ipak, njegova dela odišu postmodernom i drugačijim osećajem, kojeg nikako ne možemo nazvati modernističkim, dok tehnike kao što su pastiš, frag-

* Studentski Trg 3, 11000 Beograd. [milica.abramovic@gmail.com] 
mentacija, kolaž i metafikcija samo to potvrđuju. (Tally, 2009: 164-165) Vonegat ne samo da koristi postmodernističke tehnike u svojim romanima, on ih veoma često parodira. Patriša Vo (Patricia Waugh), u svojoj studiji o metafikciji, Vonegata ne naziva postmodernistom, već piscem metafikcije. Upoređivanjem načela metafikcije, onako kako je određeni kritičari definišu, sa vonegatovskom metafikcijom u romanu Breakfast of Champions, postaje očigledno da ovo nije klasičan primer metafikcije, već da je Vonegat izvrće i dovodi do apsurda.

Linda Hačon (Linda Hutcheon) kaže da je ,, Metafikcija [...] fikcija o fikciji - tj. fikcija koja uključuje unutar sebe komentar na sopstveno pripovedanje i/ili lingvistički identitet." Ona naziva ovakav tekst narcisoidnim da bi naznačila njegovu samosvest, i daje dva citata koja ovo objašnjavaju - citira Frojda koji kaže da je narcisizam u stvari status ,univerzalnog prvobitnog stanja čoveka", i Federmana koji kaže da je „sva dobra fikcija, u velikoj meri, odraz sebe pre nego odraz realnosti." (Hutcheon, 2014: 1, xi) Metafikcija je odlika svih romana, iako je termin nešto noviji i prvi put ga je upotrebio američki kritičar i književnik Vilijam H. Gas (William H. Gass) 1970. godine. Metafikciju Patriša Vo definiše kao tekst fikcije koji je svestan sebe kao teksta fikcije, i koji skreće čitaocu pažnju na svoju fikcionalnost, odnosno na vezu između fikcije i realnosti. Zajedničko za pisce metafikcije jeste ,,izučavanje teorije fikcije kroz pisanje fikcije". S obzirom na to da ovakvi tekstovi kritikuju sopstvene metode sastavljanja i pripovedanja, oni u isto vreme istražuju moguću fikcionalnost sveta koji postoji izvan sveta romana. Meta perspektiva je neophodna kako bi se izučavao odnos između sveta fikcije i sveta van fikcije, i kako bi se sagledao odnos između jezika, arbitrarnog lingvističkog sistema, i sveta na koji se jezik odnosi (više ne možemo gledati na jezik kao na oruđe koje pasivno oslikava uređen i objektivan svet). Ovaj odnos je problematičan, jer je nemoguće objektivno opisati svet, i metafikcija upravo postavlja pitanje - kako uopšte opisati bilo šta? Prvi problem sa kojim se susreće pisac metafikcije jeste nemogućnost da predstavi svet. Jedino što može da prikaže jesu diskursi tog sveta, ali ako pokuša da ,analizira niz lingvističkih odnosa, koristeći se istim kao oruđem analize, jezik uskoro postaje jedna vrsta zatvora iz kojeg je mogućnost bega veoma mala". Metafikcija unutar romana može se baviti prikazivanjem procesa stvaranja, može biti parodija nekog dela ili tehnike, ili istovremeno i primer i kritika nekog žanra. Metafikcijski romani su uglavnom izgrađeni na jed- 
nom osnovnom sukobu - ,stvaranju iluzije u fikciji (kao u tradicionalnom realizmu) i razotkviranju te iluzije" tj. na pisanju fikcije i pisanju o pisanju iste, tako vodeći ka konceptu dekonstrukcije. (Waugh, 1996: 2-6) Iako je metafikcija odlika postmodernizma, skoro svaki eksperimentalni tekst koristi bar neku tehniku metafikcije: ,Bilo koji tekst, koji privlači čitaočevu pažnju na sopstveni proces sastavljanja frustrirajući njena ili njegova konvencionalna očekivanja o značenju ili završetku, manje-više eksplicitno problematizuje načine na koje pripovedni kodovi - bili oni književni ili društevni - neprirodno grade naizgled realne i imaginarne svetove u pogledu određenih ideologija, istovremeno prikazujući ih kao transparentno prirodne i večne". ${ }^{\text {(Waugh, 1996: 22) }}$

Vo i Hačon prave distinkciju između različitih vrsta metafikcije. Vo najpre pravi podelu na osnovu odnosa prema jeziku. Prva vrsta metafikcije prihvata da postoji deo stvarnosti čija se ,,važnost ne zasniva u potpunosti na vezama unutar jezika", pa tako književnici kao Kurt Vonegat ili Džon Faulz (John Fowles) konvenciju izvrću na nivou strukture. Oni koriste parodiju određenog teksta ili sistema, jer smatraju da je jezik ono na čemu se zasniva svakodnevnica. Druga vrsta metafikcije smatra da je jezik jedna vrsta zatvora, i pisci ove vrste metafikcije kao Donald Bartelm (Donald Barthelm) i Išmael Rid (Ishmael Reed) narušavaju svakodnevnicu poigravajući se na nivou znaka. Ove dve vrste metafikcije razlikuje autorov stav prema realnosti. Kada govori o svakodnevnoj realnosti, Vo se poziva na sociološku studiju Bergera i Lakmana, The Social Construction of Reality (1971), koja tvrdi da nam se svakodnevnica nameće u toj meri da mi odbijamo bilo kakvu sumnju u njenu realnost i počinjemo da postojimo i verujemo u svakodnevnicu. Naše shvatanje realnosti se može samo malo izmeniti, ali nikada u potpunosti, čak i ako uvedemo meta nivoe u književni i društveni diskurs. Jezik je onaj koji nam omogućava da ostvarimo osećaj svakodnevne realnosti. (Waugh, 1996: 52-53) Pisci metafikcije se međusobno razlikuju po pitanju odnosa verbalnog i svakodnevnog.

1 “Any text that draws the reader's attention to its process of construction by frustrating his or her conventional expectations of meaning and closure problematizes more or less explicitly the ways in which narrative codes - whether 'literary' or 'social' - artificially construct apparently 'real' and 'imaginary' worlds in the terms of particular ideologies while presenting these as transparently 'natural' and 'eternal'." Prevodi na srpski jezik u ovom radu dati su od strane autora rada, osim ako nije drugačije naznačeno. 
Književnici, kao što je Vonegat, u stvari žele da nagoveste čitaocima da „realnost sigurno postoji izvan teksta, ali da se do nje dolazi kroz tekst." (Waugh, 1996: 90)

Hačon pravi razliku između dve vrste metafikcije: s jedne strane, postoje tekstovi koji su dijegetički metafikcionalni ${ }^{2} \mathrm{tj}$. ,oni su svesni svojih narativnih procesa", dok, s druge strane, postoje tekstovi koji su lingvistički metafikcionalni $\mathrm{tj}$. „svesni ograničenja i sposobnosti sopstvenog jezika”. Ove vrste metafikcije mogu se manifestovati u još dva oblika - otvoreni (u kome je jasno prisutna metafikcija, kroz teme ili alegoriju, metaforu ili komentar na pripovedanje) i prikriveni (metafikcija nije očigledna, prisutna je na nivou strukture). Dok je otvoreni oblik i samosvestan i autorefleksivan, prikriveni je autorefleksivan, ali ne mora biti samosvestan. Hačon navodi nekoliko tehnika koje se često koriste u otvorenom obliku metafikcije, i to su mise-en-abîme, alegorija, metafora, i fokusiranje na pripovedanje umesto na fikciju (kroz defamilijarizaciju - ukazivanje na elemente narativa ili tehnike na koje smo već navikli; i parodiju - često same forme romana). Hačon naglašava ulogu čitaoca u procesu stvaranja sveta fikcije - otvoreni metafikcijski tekstovi ukazivaće stalno na tu ulogu, dok će je prikriveni podrazumevati. (Hutcheon, 2014: 23, 28-30)

Kada kritičari govore o metafikciji, oni najpre govore o ramovima tj. okvirima (eng. frames), koje smatraju odlikom svih umetničkih dela - okviri postoje kako bi umetničkim delima odredili granice. Granice impliciraju da je prikazano delo samo mali segment čitavog jednog sveta koji se nalazi izvan tih granica. Odlučiti koji deo tog sveta prikazati je ono što čini umetnikov posao teškim. Bren Nikol citira Ničea koji tvrdi da priče sa granicama teraju publiku da se zapita šta je sakriveno ivicama okvira, jer sve što vidimo u umetničkim delima, vidimo zato što nam je to dozvolio umetnik. Pripovedanje predstavlja oruđe kojim se gradi portal kroz koji čitalac ulazi u fikcionalni svet. (Nicol, 2009: 36) Vonegat otvoreno u svojim romanima postavlja granice i stvara okvire. U romanu Cat's Cradle (1963) okvir predstavlja uvodna naratorova priča o tome kako piše knjigu o atomskoj bombi, i kroz priču sporadično i suptilno komentariše svoje pripovedanje. Slično se dešava i u romanu Hocus-Pocus (1990), koji počinje Vonegatovom napomenom u kojoj predstavlja sebe kao urednika, a ne kao autora romana. Narator pripoveda u prvom licu, i često govori o tome koje reči i fraze koristi

2 Neki pisci metafikcije odbacuju mimezis i okreću se diegezi - želeći tako da pričaju umesto da pokazuju. 
i zašto. ${ }^{3}$ Roman Mother Night (1961) ima metafikcijske elemente koliko i ovi prethodno spomenuti romani - u uvodnom poglavljiu Vonegat stvara okvir, u kome nam poručuje da je on samo urednik ove knjige. U romanu Galapagos (1985) narator je Leon Trotski Traut, sin nama već poznatog Kilgora Trauta ${ }^{4}$. On kao duh dolazi na ostrvo brodom na kome je poginuo i pripoveda priču na osnovu znanja koja je skupio posmatrajući evoluciju ljudske vrste u poslednjih million godina. ${ }^{5}$ Slaughterhouse-Five (1969) je klasičan primer istoriografske metafikcije, ili kako Alan Gibs (Alan Gibbs) tvrdi u svojoj studiji, primer metafikcije traume - nametanjem svog prisustva u tekst, Vonegat nas podseća da je ovaj roman daleko od striktno fiktivnog teksta (2014: 62). Metafikcija je najzastupljenija u romanu Breakfast of Champions (1973), i njene implikacije možemo primetiti u romanu Jailbird (1979), o čemu ćemo više u nastavku.

Slaughterhouse-Five je roman koji se posebno izdvaja kada govorimo o metafikciji, ${ }^{6}$ jer su svi elemeti metafikcije prisutni: komentar na stvaranje dela, refleksije o pripovedanju, likovi koji migriraju iz dela u delo, autor koji uskače u svet fikcije, postavljanje i rušenje granica između realnog i fikcionalnog sveta. Glavni lik Slaughtehouse-Five je Bili Pilgrim (Billy Pilgrim $)^{7}$, koji je kao mladić bio ratni zarobljenik u Nemačkoj za vreme

3 „U ovoj knjizi nema nepristojnih reči, ako izuzmemo „pakao” i „Bog”[...]” (Vonegat, 2014: 4) Kada daje malo duži opis obraća se čitaocima: „Molim vas da se malo strpite. Ovo je istorija." (Vonegat, 2014: 10) Preveo Zoran Paunović.

4 Kilgor Traut (Kilgore Trout) je lik koji se redovno javlja u Vonegovoj fikciji, čak u nekoliko romana. Obično se smatra Vonegatovim alter-egom. U romanu Breakfast of Champions Traut je glavni lik.

5 "[The] convention of starring certain names will continue throughout my story, incidentally, alerting readers to the fact that some characters will shortly face the ultimate Darwinian test of strength and willingness." (Vonnegut, 1994: 24)

6 Ovo je tačnije istoriografska metafikcija, kako ju je definisala Linda Hačon u svojoj studiji Historiographic Metafiction Parody and the Intertextuality of History koja se može pronaći na internet adresi: https://tspace.library.utoronto.ca/bitstream/1807/10252/1/TSpace0167.pdf

7 Vo govori o imenovanju likova, kao o bitnom procesu u metafikciji, koji zavisi upravo od toga koliko autor drži do iluzije realnosti. Ova tehnika podseća na fikciju 18.veka, ali metafikcija nema nameru da potvrdi ovu tehniku kao validnu, već naprotiv, želi da potvrdi da u fikciji imena mogu da istovremeno opisuju i označavaju, i da „ono što je označeno je već stvoreno kroz sami proces imenovanja." Kao primer, između ostalih, uzima i Bilija Pilgrima, čije ime Pilgrim u prevodu naseljenik ustvari opisuje našeg glavnog lika, koji na kraju stvarno biva naseljenik na jednoj vanzemaljskoj planeti, ali i ukazuje na to da je samim 
Drugog svetskog rata. Verovatno pod uticajem posttraumatskog stresnog poremećaja nasumično doživljava trenutke iz svog života. Na početku romana Vonegat govori o tome kako je bilo teško napisati tu apsurdnu ${ }^{8}$ knjižicu. ${ }^{9}$ Koliko god se trudio, knjiga je na kraju ispala kratka, ispreturana i neskladna, i čini se da tako mora biti kada se govori o masakrima, kao što je bio Drezden. ${ }^{10}$ On alegorično piše o svojim tehnikama pripovedanja kada objašnjava načine komunikacije na vanzemaljskoj planeti Tralfamador $^{11} \mathrm{i}$ tralfamadorske poruke (u intervjuima na sličan način govori o vicevima za koje kaže da predstavljaju osnovu njegovih romana ${ }^{12}$ ). U romanu Slaughterhouse-Five se pojavljuje i jedan od učestalih Vonegatovih likova

imenovanjem on to postao. Za metafikciju je karakteristična težnja da razotkrije upravo taj „paradoks stvaranja, odnosno opisivanja” - metafikcija ne želi da prikazuje svet, već diskurse koji grade taj svet. (Waugh, 1996: 94, 100)

8 „Znate li šta ja kažem ljudima kada čujem da pišu antiratne knjige? [...]Kažem: „Zašto umesto toga ne napišete jednu anti-ledničku knjigu?” On je, naravno, time mislio da će uvek biti ratova, da ih je isto toliko lako zaustaviti kao lednike. I ja tako mislim." (Vonegat, 2001: 9) Prevodi na srpski prezueti su iz :Vonegat, K. (2001). Klanica-PET ili dečji krstaški rat. Preveo sa engleskog Branko Vučićević. Beograd: Narodna Knjiga Alfa. U originalu: Vonnegut. K. (1969). SlaughterhouseFive or The Children's Crusade. New York: Delacorte Press.

9 „Bilo bi mi odvratno da vam pričam koliko me je ova drljava knjižica stajala novca i nemira i vremena." (Vonegat, 2001: 8)

10 „[Ova knjiga] je ovako kratka i ispreturana i neskladna, Seme, jer o pokolju nema šta pametno da se kaže. Smatra se da su svi mrtvi, da više nikad ne treba ništa da kažu ili žele."(Vonegat, 2001: 24)

11 “...] svaka skupina simbola predstavlja jednu kratku, hitnu poruku - opisuje neku situaciju, neki prizor. Mi, Tralfamadorci, čitamo ih sve odjednom, ne jednu za drugom. Između svih tih poruka ne postoji nikakva posebna veza, sem što ih je autor pažljivo odabrao tako da, kad se sve odjednom sagledaju, proizvode sliku života, koja je lepa i iznenađujuca i duboka. Nema početka, nema sredine, nema kraja, nema napetosti, nema pouke, nema uzroka, nema posledica. Ono sto volimo u svojim knjigama jesu dubine mnogih čudesnih trenutaka koji se svi istovremeno sagledavaju." (Vonegat, 2001: 85)

12 "I build jokes. I find sections of my book constructed like jokes and then they're not very long and I suddenly realize the joke is told, and that it'd spoil the joke if I were to go past. The tag line is where the joke paid off and so I'll make a row of dots across the page to indicate that something's ended and I'll begin again and it's essentially built as another joke." (Clancy, 1988: 46)

"My books are essentially mosaics, thousands and thousands of tiny little chips all glued together, and each chip is this thing I learned to do- this thing I learned to make as a child- which is a little joke." (McLaughlin, 1988: 69) 
- Kilgor Traut ili Vonegatov literarni alter-ego. Vonegat stalno podseća čitaoce na svoje prisustvo uključujući u romane Trautove naučnofantastične priče, koje ne samo da kroz alegoriju predstavljaju Vonegatove stavove, već povezuju intertekstualno sve njegove romane ${ }^{13}$. Vonegat pokušava da ostvari kontakt sa svojim likovima - u predgovoru on kaže da kada malo više popije zove telefonom ljude sa kojima je bio u ratu, nekad ih dobije, nekad ne. Jedne večeri Biliju Pilgrimu zazvoni telefon: „Bili se javio. Na drugoj strani je bio neki pijanac. Bili je skoro mogao da oseti njegov dah - iperit i ruže. ${ }^{14}$ Pogrešan broj. Bili prekide vezu." (Vonegat, 2001: 71) Bio je to ispravan broj telefona - Vonegat pokušava da uspostavi vezu sa svojim fiktivnim likom. Ovo nije uobičajeni roman i nema likove i zaplete na kakve smo navikli. ${ }^{15}$ Fantastični svet u Slaughterhouse-Five, koji je predstavljen uz pomoć planete Tralfamador, predstavlja i jedan paralelni svet umetnosti i stvaranja. Patriša Vo posebno govori o Slaughterhouse-Five, kao o romanu metafikcije, ali i kao o romanu u kome se autorovi filozofski stavovi ogledaju u formi romana koja omogućava stvaranje dodatnih svetova - realni svet u kome je Vonegat autor knjige o Drezdenu, fikcionalni svet Bilija Pilgrima i ultra-fikcionalni svet vanzemaljske planete Tralfamador. Bili se povlači u prostor iz kojeg može na ovaj masakar u Drezdenu da gleda sa određene distance, i to je ono što mu Tralfamador pruža. ${ }^{16}$ (Waugh, 1996: 127)

13 Kao što Vonegat nije pisac naučne fantastike tako to nije ni Traut - on je pisac alegorija. Bar u par romana, kao što su Jailbird i Slaughterhouse-Five, naići ćemo na komentare na Trautovu prozu - likovi tvrde da su Trautovi romani dobri zbog ideja, dok je stil očajan: „Isuse, kad bi Kilgor Traut samo umeo da piše! - uzviknu Rouzvoter. Tu je bio u pravu: nepopularnost Kilgora Trauta bila je zaslužena. Njegova proza bila je grozna. Samo su mu ideje bile dobre." (Vonegat, 2001: 104) Ove komentare možemo sagledati iz perspektive metafikcije onda kada pročitamo Vonegatov esej „How to write with style” u kome i sam govori da je na kraju krajeva mnogo važnije preneti dobru ideju nego se zamarati stilom (Vonnegut, 1980).

14 U uvodu romana tako Vonegat opisuje svoj dah.

15 „U ovoj priči skoro uopšte nema karaktera ni dramskih sukoba, jer je većina ljudi u njoj toliko bolesna i u tolikoj meri bezvoljna igračka ogromnih sila. Na kraju krajeva, jedan od glavnih efekata rata i jeste da ljude obeshrabruje da budu karakteri." (Vonegat, 2001: 151-152)

16 U romanu Hocus-Pocus ima naznake, pri kraju romana, da je priču o Trafalmadoru napisao Vonegatov alter-ego, Kilgor Traut, pa možemo tako pretpostaviti da je Bili Pilgrim ideju o odlasku na drugu planetu pročitao u Trautovom romanu, i, kao Dvejn Huver (Dwayne Hoover) u romanu Breakfast of Champions, preozbiljno je shvatio. Dvejn umišlja da je jedino ljudsko biće na planeti mašina, a Bili umišlja da putuje na vanzemaljsku planetu. 


\section{Parodija metafikcije u romanu Breakfast of Champions}

„,[Ovaj roman] je eksperimentalne prirode. Ne znam kako će da ispadne i kakvo će mu biti značenje, ali sam osmislio situaciju u kojoj samo jedna osoba u univerzumu ima slobodnu volju, koja mora da odluči šta će da uradi sledeće i zašto, koja se pita šta se zapravo dešava i šta bi trebalo da uradi. Svi ostali su roboti, i tvorac univerzuma misli da bi možda bića sa slobodnom voljom bila pogodna bića da se postave na neku planetu, pa tako On izvodi taj eksperiment na Zemlji. Ovaj čovek je prodavac Pontijaka u Indijanapolisu, ali je on jedina osoba koja razmišlja, jer su svi ostali programirani da budu to što jesu. Koje su implikacije ovoga ne znam, ali sada izvodim eksperiment." (Clancy, 1988: 49) ${ }^{17}$ Ovako je u jednom intervjuu 1971. godine Vonegat pričao o knjizi koju je tada tek počeo da piše. Breakfast of Champions je roman u kome uporedo pratimo živote dvojice glavnih likova, Kilgora Trauta i Dvejna Huvera, koji su dve dijametralno suprotne ličnosti, i čiji susret izaziva haos u gradiću Midlendu. Na jednom kraju Amerike živi nepoznati pisac naučne fantastike, koji je na putu ka ogromnoj slavi, a na drugom kraju zemlje uspešni biznismen na putu ka totalnoj propasti. Poslednju kap u Huverovoj časi šizofrenije predstavlja Trautov roman, koji ga u potpunosti ubedi da je on jedino ljudsko biće u moru mašina. ${ }^{18}$ Ova šarmantna i uznemirujuća priča često biva

17 'It's in the nature of an experiment. I don't know how it's going to come out or what the meaning's going to be-but I've set up a situation where there's only one person in the whole universe who has free will, who has to decide what to do next and why, has to wander what's really going on and what he's supposed to do. Everybody else is a robot and the creator of the universe thinks that perhaps free-will creatures would be good creatures to put on some planet and so He performs this experiment on Earth. This man is a Pontiac dealer out in Indianapolis, but he's the only person who is thinking because everybody else is programmed to be what he has to be. What the implications of this are I don't know, but I'm running off the experiment now."

"This is a tale of a meeting of two lonesome, skinny, fairly old white men on a planet which was dying fast. One of them was a science-fiction writer named Kilgore Trout. He was a nobody at the time, and he supposed his life was over. He was mistaken. As a consequence of the meeting, he became one of the most beloved and respected human beings in history. The man he met was an automobile dealer, a Pontiac dealer named Dwayne Hoover. Dwayne Hoover was on the brink of going insane." (Vonnegut, 2000: 7) 
prekinuta naratorovim autobiografskim opaskama ${ }^{19}$, refleksijama o knjizi ${ }^{20}$, naučnofantastičnim pričama ${ }^{21}$ i Vonegatovim pojavljivanjima u romanu ${ }^{22}$. Vo navodi studiju o postmodernizmu Dejvida Lodža (David Lodge) u kojoj on govori o postmodernističkim tehnikama kao što su kontradikcija, permutacija, diskontinuitet, nasumičnost, neumerenost i kratki spoj. Metafikcija se posebno oslanja na kontradikciju, permutaciju i kratki spoj. Vo tvrdi da se kontradikcija u metafikciji može najbolje ilustrovati paradoksom lažljivca - ,svi romanopisci su lažljivci, reče iskreno pisac metafikcije". U romanu Slaughterhouse-Five je upotrebljena kontradikcija tako što su predstavljeni kontradiktorni svetovi. Kontradikcija uključuje paradoks, koga samo može rešiti beskonačnost, što uključuje beskrajno ponavljanje. Ulazak autora u fikcionalni svet je vrsta paradoksa - on nestaje iz realnog sveta onda kada se pojavljuje u fikcionalnom, i obrnuto. Još jedan način da se ukaže na ovo beskonačno cirkulisanje jeste upotreba tehnike priča $u$ priči. Priča unutar priče mora biti pažljivo uokvirena, jer u suprotnom ne možemo uočiti granice, a ni rušenje tih granica - tekst postaje nasumičan. Neki autori koriste tehniku nagomilavanja parčadi stvarnog života, koji možda nisu od direktne važnosti za tekst, ali pažljivo upotrebljeni mogu doprineti atmosferi dela. Bartelm u svom postmodernom romanu Snow White (1967) koristi deliće raznih diskursa američke kulture đubreta. On njih naziva nervoznim predmetima (eng. anxious objects), jer oni ne znaju da li su đubre ili umetnost. Vonegat takođe namerno stvara ove nervozne predmete, dela koja sumnjaju da su đubre. ${ }^{23}$ (Waugh, 1996: 137-144)

19 "Dwayne Hoover had oodles of charm.I can have oodles of charm when I want to." (Vonnegut, 2000: 20)

20 "What do I myself think of this particular book? I feel lousy about it, but I always feel lousy about my books. My friend Knox Burger said one time that a certain cumbersome novel "...read as though it had been written by Philboyd Studge." That's who I think I am when I write what I am seemingly programmed to write." (Vonnegut, 2000: 4)

21 Vonegat obilato koristi pripovedačku tehniku priče u priči tako što često ubacuje Trautove naučnofantastične priče.

22 Vonegat ima ulogu autora ili naratora sopstvenog romana, ali se u njemu pojavljuje i kao lik.

23 "So this book is a sidewalk strewn with junk, trash which I throw over my shoulders as I travel in time back to November eleventh, nineteen hundred and twenty-two." (Vonnegut, 2000: 6) 
Pisci metafikcije često osećaju da moraju da brane svoj pristup pisanju koristeći se ponekad ekstremnim defanzivnim tehnikama. Vo gleda na Vonegatov roman Breakfast of Champions kao na pokušaj da se predstavi apsurd koji proizilazi iz autorovog stanja koje ga goni da izjavi da više nema kulturu i da više ne može tako da živi. ${ }^{24}$ Vonegatovi pokušaji da upotrebi precizne opise su često neuspešni, pa tako ilustracije ${ }^{25}$ zamenjuju jezička pomagala da bi na drugačiji način prikazale kulturu dubreta. ${ }^{26}$ Vonegat $\mathrm{u}$ ovom romanu predstavlja jednu novu realnost u kojoj su vanzemaljci ti koji pokušavaju da razumeju strani/ Zemaljski svet - tako autor preokreće konvencije naučne fantastike. Američko društvo predstavljeno je kao vanzemaljsko uz pomoć naratora koji sa Zemlje odlazi na vanzemaljsku planetu. Time što je narator u poziciji da vanzemljcima objašnjava kako funkcioniše život na Zemlji, autor koristi tehniku defamilijarizacije, koja je karakteristična za metafikciju. Vo smatra da ova tehinka ima satiričku funkciju, ali i da pokazuje da je Vonegat svestan da ne može da „prikaže kritiku prihvaćenih kulturnih oblika predstavljanja unutar tih istih oblika". (Waugh, 1996: 8) Breakfast of Champions je kolaž u kome su uklopljeni razni žanrovi, teme, ideje i likovi - sve ono što je karakteristično za Vonegatovu prozu. Ovaj roman je poseban zato što se metafikcija dovodi na viši nivo u odnosu na prethodne romane. Vonegat nije samo komentator svoje tehnike pripovedanja ili postupaka svojih likova, već on ima određenu vrstu interakcije sa njima, postaje žrtva njihovih postupaka. Ovo više nije ona prethodno definisana metafikcija, sada je to, kako je Tali naziva, hiperfikcija ili možda čak patafikcija, jer naglašava apsurd ove tehnike, kao što patafizika Alfreda Džarija (Alfred Jarry) parodira metafiziku (Tally, 2009: 174). Parodija metafikcije ogleda se u savršenom primenjivanju principa metafikcije i izvrtanju tih principa. Poteškoću u razumevanju romana Breakfast of Champions predstavlja problematični odnos autora i naratora, što kasnije problematizuje odnos autor-narator-lik i naravno odnos autor-narator-tekst, koji je od ključne važnosti za metafikciju.

24 "I have no culture, no humane harmony in my brains. I can't live without a culture anymore." (Vonnegut, 2000: 5)

25 U romanu se javlja mnoštvo autorovih ilustracija koje prikazuju jednostavne predmete i simbole.

26 "I think I am trying to clear my head of all the junk in there- the assholes, the flags, the underpants. Yes - there is a picture in this book of underpants. I'm throwing out characters from my other books, too. I'm not going to put on any more puppet shows. I think I am trying to make my head as empty as it was when I was born onto this damaged planet fifty years ago.” (Vonnegut, 2000: 5) 
Metafikcijski romani ne priznaju tradicionalnog autora kao transcendentalno biće koje uz pomoć mašte i diskursa, koji je u suštini monolog, stvara novi uređeni svet - autor je samo proizvod već postojećih tekstova. (Waugh, 1996: 16) To je nešto sa čime se Vonegat očigledno slaže. ${ }^{27}$ "Znam ko je izmislio Kilgora Trauta. Ja sam to učinio." 28 Upotreba zamenice ja potvrđuje da je narator romana i autor istog. Grir tvrdi da ovo nije baš tako jednostavno kako se čini, i navodi Klinkovica koji kaže da se kod Vonegata oseća borba koju on vodi sa sobom u cilju razdvajanja autora i naratora. ${ }^{29}$ Ukoliko smatramo da Vonegat koristi zamenicu ja tako što personalizuje naratora, ili ukoliko se Vonegat poistovećuje sa svojim likom (kada se pojavi u romanu), onda je odnos autor-tekst pogrešno predstavljen. U onoj meri u kojoj se Vonegat poistovećuje sa svojim naratorom ili sa Kilgorom Trautom (kao svojim literarnim alter egom) u toj meri se on ne može otcepiti od njih. Kao lik u romanu Breakfast of Champions, Kilgor Traut je pisac naučne fantastike $\mathrm{i}$ autor svojih tekstova, ali je i pseudonim pisca $\mathrm{u}$ romanu Jailbird, što dovodi do nekoliko problema u odnosu autor-tekst (šizofrenija, pseudonimija i određivanje granica). Narator romana Breakfast of Champions utiče na tekstualnu šizofreniju, ali uzima šizofreniju i kao temu (kaže za sebe da sumnja da je bolestan, ${ }^{30}$ a i glavni lik romana, Dvejn Huver, pati od istog poremećaja sa simptomima kao što su eholalija i paranoja). Naratora ovog romana ne možemo razdvojiti od Kurta Vonegata, ali u isto vreme nismo sigurni da je narator zapravo Kurt Vonegat, tako nemogućnost razlučivanja između stvarnosti i fikcije postaje prvi korak ka šizofreniji teksta. Narator pokušava da uzdigne sebe iz pozicije lika

27 "As for myself: I had come to the conclusion that there was nothing sacred about myself or about any human being, that we were all machines, doomed to collide and collide and collide. For want of anything better to do, we became fans of collisions. Sometimes I wrote well about collisions, which meant I was a writing machine in good repair. Sometimes I wrote badly, which meant I was a writing machine in bad repair. I no more harbored sacredness than did a Pontiac, a mousetrap, or a South Bend Lathe." (Vonnegut, 2000: 219-220)

28 "I do not know who invented the body bag. I do know who invented Kilgore Trout. I did./ I made him snaggle-toothed. I gave him hair, but I turned it white. I wouldn't let him comb it or go to a barber. I made him grow it long and tangled./ I gave him the same legs the Creator of the Universe gave to my father when my father was a pitiful old man. They were pale white broomsticks. They were hairless. They were embossed fantastically with varicose veins." (Vonnegut, 2000: 32)

29 Klinkowitz, J. (1982). Kurt Vonnegut. London: Methuen. (pp. 43)

30 "I did not and do not know for certain that I have that disease" (Vonnegut, 2000: 194). 
u poziciju sile izvan teksta ${ }^{31}$. Grir smatra problematičnim to što narator romana tvrdi da je autor istog, i navodi Fukoa koji kaže da se čak ni roman koji je pripovedan u prvom licu nikada ne odnosi na pisca i da se uloga autora otkriva onda kada je potrebno napraviti distinkciju između autora i naratora. ${ }^{32}$ Kada se autor pojavi u tekstu, kao što to Vonegat često čini, on se može tumačiti kao lik koji jednostavno glumi ulogu autora - ovakvo određivanje uloga je postalo često u savremenoj književnosti kao oruđe uz pomoć koga autor iskazuje svoja mišljenja o pisanju. „Čak kada bi narator nazvao sebe Kurtom Vonegatom, on bi i dalje bio samo narator ili lik po imenu Kurt Vonegat - ime Kurt Vonegat ne bi bilo odvojeno od dela, ali bi Kurt Vonegat, osoba, bio još više udaljen. Reći „Ja sam autor ovog teksta, ja sam Kurt Vonegat,” ne poistovećuje čoveka sa naratorom, ja nazvano Kurt Vonegat, već naglašava njihovo postojanje kao reči. Kada bi Vonegat, kao kritičar potvrdio, da, ja sam narator romana Breakfast of Champions, Kilgor Traut je moj lik, još više bi se udaljio od svog dela, postavši kritičar koji govori o autoru koji piše o naratoru koji tvrdi da je autor." ${ }^{33}$ (Greer, 1989: 312-314)

Čini se da roman Breakfast of Champions kroz sopstvenu šizofreniju postaje tekst bez autora. Pisac ovog romana kaže da je pokušavao da se drži na distanci od haosa koji je napravio. Ipak, on biva umešan u taj haos više puta

31 "The bartender took several anxious looks in my direction. . . . I did not worry about his asking me to leave the establishment. I had created him, after all .... [H] e went on staring at me, even though I wanted to stop him now. Here was the thing about my control over the characters I created: I could only guide their movements approximately, since they were such big animals." (Vonnegut, 2000: 202)

32 "It is well known that in a novel narrated in the first person, neither the first person pronoun, the present indicative tense, nor, for that matter, its signs of localization refer directly to the writer, either to the time when he wrote, or to the specific act of writing." Foucault, M. (1977). What Is an Author. Translated by Donald E. Bouchard and Sherry Simon. In Bouchard, D.E. (ed.). Language, CounterMemory, Practice. Ithaca: Cornell University Press. (pp. 129)

33 "Even if the narrator had named himself Kurt Vonnegut, he would still only be a narrator or character named Kurt Vonnegut- the name Kurt Vonnegut would not be separate from the work, but Kurt Vonnegut the person would be even farther removed. To say, "I am the author of this text, I am Kurt Vonnegut," does not identify the human being with the narrator, the "I" named Kurt Vonnegut, but emphasizes their "existence" as words. If, as a critic, Vonnegut asserted that, yes, "I" am the narrator of Breakfast of Champions, Kilgore Trout is "my" character, he would remove himself even farther from "his" work, becoming then a critic speaking of an author who writes of a narrator who claims authorship." 
i povređen. ${ }^{34}$ Narator, na taj način, ismeva ideju granice između autora i svoje fikcije. Udaljiti se od teksta znači pisati o likovima, odnosno pretpostaviti da autor može da izmisli lika i tako postavi granice između sebe i svoje fikcije. Kad počne da postoji kao lik u svojoj fikciji, autor prestaje da postoji kao autor. Da li isto važi i za njegove fiktivne likove - onda kada nisu više fiktivni, kada imaju interakciju sa autorom koji je stvaran - koji im je status? ${ }^{35}$ Prelaženje granica teksta predstavlja klimaks romana - Dvejn Huver pročita priču Kilgora Trauta i odmah poveruje u nju (i Dvejn Huver i ta priča su fikcionalni, ali na različitim nivoima). Nemoguće je napraviti razliku između stvarnog sveta Dvejna Huvera (koji je za nas fikcionalni svet) i fikcionalnog sveta Trautove priče (koji je za nas fikcionalni svet unutar fikcionalnog sveta), pa je tako nemoguće opisati naratora romana Breakfast of Champions kao odvojeni entitet u odnosu na tekst i druge likove. Ukoliko posmatramo ovaj tekst kroz prizmu autor kao lik i obrnuto, onda tvrdimo da su autor i lik odvojeni. Ova podela postaje besmislena kada Traut pita naratora da li je i on učesnik Festivala umetnosti u Midlendu, a narator odgovara da je on sa Festivala Svega ${ }^{36}$. Pisac pati od šizofrenije, bar kako on tvrdi, ${ }^{37}$ i Grir ovakave naratorove izjave povezuje sa tvrdnjama da oni koji pate od šizofrenije ne mogu izgovoriti reč ja. Narator želi da potvrdi da mu je bolje tako što stalno ponavlja tu reč, jer smatra da tako uspeva da postavi granicu između sebe i drugih, ili sebe i teksta koji piše. Koliko god narator tvrdio da je autor izvan teksta, to jednostavno nije

34 "As for myself: I kept a respectful distance between myself and all the violence even though I had created Dwayne and his violence and the city, and the sky above and the Earth below. Even so, I came out of the riot with a broken watch crystal and what turned out later to be a broken toe. Somebody jumped backwards to get out of Dwayne's way. He broke my watch crystal, even though I had created him, and he broke my toe." (Vonnegut, 2000: 274)

35 „The thing was: Trout was the only character I ever created who had enough imagination to suspect that he might be the creation of another human being. He had spoken of this possibility several times to his parakeet. He had said, for instance, "Honest to god, Bill, the way things are going, all I can think of is that I'm a character in a book by somebody who wants to write about somebody who suffers all the time." (Vonnegut, 2000: 240-41)

36 "I am from the Everything festival" (Vonnegut, 2000: 291).

37 "This much I knew and know: I was making myself hideously uncomfortable... by refusing to believe what my neighbors believed. I am better now. Word of honor: I am better now. I was really sick for a while, though. I sat there in the lounge of my own invention, and stared through the leaks at a white cocktail waitress of my own invention." (Vonnegut, 2000: 194) 
moguće - narator romana Breakfast of Champions je deo svog teksta onoliko koliko je Huver deo Trautovog. (Greer, 1989: 315-317) Ovakvu metafikciju možemo nazvati šizofrenom metafikcijom, jer nismo sigurni ko je uopšte Kurt Vonegat i ko je onaj ko piše refleksivno o pisanju. Ovo je jedan od primera kako Vonegat dovodi principe metafikcije do apsurda.

Metafikcija se bavi odnosom realnog i fikcionalnog sveta. Trautovo insistiranje da ogledala zove pukotinama (eng. leaks) i da zamišlja da su ona portal u drugi univerzum ${ }^{38}$, aludira upravo na to da se pokušaj da se u fikcionalnom oslika realni svet mora završiti rušenjem granica između fiktivnog i realnog. Kada se lik Vonegata prvi put pojavljuje u romanu, on nosi naočare koje po svojoj sličnosti ogledalima predstavljaju portal u drugu dimenziju pogled iz realnosti u fikciju ${ }^{39}$. Primer ovakvog shvatanja odnosa realnosti i fikcije jeste i prethodno spomenuti odnos između autora i naratora, odnosno autora i lika, tj. naratora i lika, ili pak autora i teksta itd. S jedne strane, čini se da roman Breakfast of Champions metaforički prikazuje odnos između pisca i njegovog dela. Pisac je jedino ljudsko biće u tom procesu, dok su svi likovi u njegovoj knjizi mašine koje on stvara, koje se ponašaju na određeni način zbog toga kako su programirane ili kako su im povezane žice $e^{40}$. Ubrzo saznajemo da nije baš tako. Pisac izmišlja priču i likove. On upravlja njima i

38 "Trout did another thing which some people might have considered eccentric: he called mirrors leaks. It amused him to pretend that mirrors were holes between two universes. If he saw a child near a mirror, he might wag his finger at a child warningly, and say with great solemnity, "Don't get too near that leak. You wouldn't want to wind up in the other universe, would you?" (Vonnegut, 2000: 19) "I had come to the Arts Festival incognito. I was there to watch a confrontation between two human beings I had created: Dwayne Hoover and Kilgore Trout. I was not eager to be recognized. [...] I had bought a pair of sunglasses at a Holiday Inn outside of Ashtabula, Ohio, where I spent the night before. I wore them in the darkness now. They looked like this: [...] The lenses were silvered, were mirrors to anyone looking my way. Anyone wanting to know what my eyes were like was confronted with his or her own twin reflections. Where other people in the cocktail lounge had eyes, I had two holes into another universe. I had leaks. "Can you see anything in the dark, with your sunglasses on?" she asked me. "The big show is inside my head," I said." (Vonnegut, 2000: 201)

40 "So it is a big temptation to me, when I create a character for a novel, to say that he is what he is because of faulty wiring, of because of microscopic amounts of chemicals which he ate or failed to eat on that particular day." (Vonnegut, 2000: 4) 
njihovim postupcima ${ }^{41}$, i u svakom trenutku zna šta će se desiti sledeće ${ }^{42}$. Vonegat takvo znanje ne poriče - odmah nam kaže koji će biti ishod i naglašava da njega predstojeći događaji ne mogu iznenaditi. Ali kada Rabo Karabekian održi govor o značaju umetničkog dela i njegovoj simbolici, Vonegat je iznenađen njegovim rečima. ${ }^{43}$ Vonegat tako izvrće metafikciju - on je taj koji stvara svoje likove, ali ujedno ne može da ih kontroliše. ${ }^{44} \mathrm{Mi}$ od njega ne možemo očekivati da poštuje pravila čak i ako su to pravila koja je sam odredio. Slobodna volja nije sadržana u pravilima nego upravo u haosu. Vo, na primer, govori o tome kako Mjuriel Spark (Muriel Spark), gleda na pojam slobode koji je od velike važnosti za tekst metafikcije. Likovi su zarobljeni u knjizi koju piše autor, a ljudi u knjizi koju piše Bog. Tu se uočava analogija između fikcije i života - ideja da smo svi zarobljeni u priči koju neko drugi smišlja. Džon Faulz smatra da samo može biti autorska igra tvrditi da likovi mogu imati slobodnu volju (Waugh, 1996: 119), kao što to Vonegat nagoveštava u romanu Breakfast of Champions. Svrha postojanja njegovih likova jeste da mu omoguće pogled u jedan novi svet, da budu njegove oči i uši. ${ }^{45} \mathrm{Na}$ ovaj način Vonegat parodira metafikciju, tj. stvara patafikciju.

41 "Give me a Black and White and water," he heard the waitress say, and Wayne should have pricked up his ears at that. That particular drink wasn't for any ordinary person. That drink was for the person who had created all Wayne's misery to date, who could kill him or make him a millionaire or send him back to prison or do whatever he damn pleased with Wayne. That drink was for me." (Vonnegut, 2000: 192,193)

42 "As for the fortune I might have told for the waitress, this was it: "You will be swindled by termite exterminators and not even know it. You will buy steel-belted radial tires for the front wheels of your car. Your cat will be killed by a motorcyclist named Headley Thomas, and you will get another cat."(Vonnegut, 2000: 204)

43 "Karabekian slid off his barstool so he could face all those enemies standing up. He certainly surprised me. I expected him to retreat in a hail of olives, maraschino cherries and lemon rinds. But he was majestic up there [...]." (Vonnegut, 2000: 221)

44 "Here was the thing about my control over the characters I created: I could only guide their movements approximately, since they were such big animals. There was inertia to overcome. It wasn't as though I was connected to them by steel wires. It was more as though I was connected to them by stale rubberbands." (Vonnegut, 2000: 202)

45 "There was a message written in pencil on the tiles by the roller towel. This was it: [What is the purpose of life?]. Trout plundered his pockets for a pen or pencil. He had an answer to the question. But he had nothing to write with, not even a burnt match. So he left the question unanswered, but here is what he would have written, if he had found anything to write with: "To be the eyes and ears and conscience of the Creator of the Universe, you fool." (Vonnegut, 2000: 67) 
Strategije metafikcije, kao i strategije postmodernizma uopšte, ponekad se čine samo kao nastavak modernističkih tehnika, s obzirom na to da su sve one zapravo reciklirane. Kada je u pitanju roman sa više naratora ili perspektiva, ukoliko dođe do promene perspektive, u modernizmu, čitalac ima prostora da se na nju navikne. U metafikciji je slučaj nešto drugačiji. Kontradiktorni svetovi istovremeno postoje - likovi iz fikcionalnog mogu preći u realni svet, a autor iz realnog u svet romana. Ovaj problem se rešava ili kroz ,svesnost lingvističke realnosti samog teksta" ili kroz ,prihvatanje postojanja međusobno isključivih realnosti ili svetova." (Waugh, 1996: 102-103) Neki pisci metafikcije upotrebljavaju tu tehniku takozvanog loma okvira (eng. frame-breaking) kada autor uskače u svet fikcije. Ovaj lom okvira ili prelaženje granica narativa nije nova odlika književnosti karakteristična za postmodernizam i javlja se još u književnosti od 17. veka. (Nicol, 2009: 37) Vonegat ulazi u roman, posmatra svoje likove, komentariše njihove postupke, tvrdi da, kao njihov Tvorac, on zna šta im sledi u budućnosti, ali ponekad nije siguran zašto postupaju na određeni način. To nije najzanimljiviji aspekt ovog nestabilnog odnosa između likova i njihovog tvorca. Njegova interakcija sa sopstvenim likovima se ne završava baš najbolje. Kada se susretne sa Huverom, u haosu koji nastaje, završava sa slomljenim prstom na nozi. Baš onda kada je doneo odluku da se drži po strani on biva uvučen u nasilje i povređen. Kasnije, na putu da se sretne sa Trautom i podari mu slobodnu volju, kaže da se ničeg nije plašio, što smatra suludim, posebno kada imaš posla sa tako opasnim materijalom. ${ }^{46}$ Nenadano (važno je naglasiti da je bilo nenadano, zato što nije trebalo biti), jedan od likova koji se često javlja u Vonegatovim romanima, pas Kazak, napadne Vonegata i Vonegatu se od straha povuku testisi u abdomen ${ }^{47}$. Iako bi Vonegat trebalo da ima kraljevski tretman kada uskoči u sopstveni roman, jer lako može

46 "When I got out of my Plymouth Duster, I feared nothing. That was foolish of me. A writer off-guard, since the materials with which he works are so dangerous, can expect agony as quick as a thunderclap. / I was about to be attacked by a Doberman pinscher. He was a leading character in an earlier version of this book." (Voonegut, 2000: 285)

47 "But my body took one defensive measure which I am told was without precedent in medical history. It may have happened because some wire short-circuited or some gasket blew. At any rate, I also retracted my testicles into my abdominal cavity, pulled them into my fuselage like the landing gear of an airplane." (Vonnegut, 2000: 289) 
kontrolisati postupke svojih likova, dešava se upravo suprotno. Kako ih on ne može u potpunosti kontrolisati, fikcija može reagovati na neočekivane načine na njegov prestup. Fikcija se opire realnosti ${ }^{48} \mathrm{i}$ pokušava da dâ sve od sebe da izbaci uljeza - koji bi u ovom slučaju bio Vonegat kao realna ličnost koja se pretvara da je fikcionalni lik. Prvi znak upozorenja bio je onaj slomljeni prst na nozi, ali se Vonegat ne predaje. Pre nego što uspe da podari fikcionalnom liku slobodnu volju, posebno agresivni pas pokuša da ga preplaši i natera da odustane od prvobitnog plana. Međutim, fikcija ne uspeva da izbaci Vonegata, i on ipak razgovara sa Trautom. Vonegat želi da oslobodi Trauta, ali prvo mora da ga ubedi da su njegove sumnje da je fiktivni lik zapravo istinite. Tako ga šalje na Bermude na nekoliko sekundi ili u praznoj ruci projektuje prikaze koje samo Traut može videti. ${ }^{49}$

Na kraju narator oslobađa Trauta, koji je sada slobodan da živi svoj život tj. više nije lik u fikciji. Ovaj roman problematizuje ideju da tekst može da se odnosi na stvarnost izvan njega samog. Ako još uzmemo u obzir i to da je Traut Vonegatov alter-ego, i da Vonegat piše čitav roman da bi se sukobio sa fiktivnom verzijom sebe i oslobodio je iz fikcije, na metafikciju u ovom romanu moramo gledati iz ugla parodije. Trautovo putovanje se nastavlja posle romana Breakfast of Champions. Nakon susreta sa Vonegatom Traut je oslobođen da slobodno živi i stvara. U realnom svetu on izdaje knjigu ${ }^{50}$, ali kako taj poduhvat ne biva uspešan, on se

48 Možemo uporediti fikciju, koja se opire promenama iz realnog sveta, sa prošlošću koja se opire promenama iz sadašnjosti. Veoma često u pričama o putovanju u prošlost, prošlost ne dozvoljava da bude promenjena. U romanu Stivena Kinga 11.22.63 (2011) o putovanju u prošlost sa ciljem da se zaustavi atentat na Kenedija, kada god glavni lik pokuša da uradi nešto što će promeniti prošlost on se ubrzo nađe u situaciji u kojoj mu je ugrožen život - i tako se prošlost opire promeni. Tako nešto kao da se dešava sa Vonegatom kada pokušava da bude tamo gde mu nije mesto - kao lik u sopstvenoj fikciji.

49 "I had nothing in my hand ... [h] se saw that I held an apple ..." (Vonnegut, 2000: 293).

50 Venus on the Half-Shell (1974) je naučnofantastični roman napisan pod pseudonimom Kilgor Traut, dok je pravi autor Philip José Farmer. Sve je počelo od priče koju je napisao Vonegat, ali potpisao pseudonimom Traut, i koja se pojavila u romanu God Bless You, Mr. Rosewater (1965). Farmer je iz te priče kasnije razvio čitav roman. U slučaju Venus on the Half-Shell pseudonimija predstavlja problem stvaranja granica izmedju fikcionalnog i realnog sveta. Ime fikcionalnog lika (Kilgor Traut) uzeto je kao pseudonym za izdavanje knjige u realnom svetu. Ovo onda biva knjiga koju izdaje Kilgor Traut i koja nikakve veze nema sa Kurtom Vonegatom. Kao što ime Kilgor Traut na koricama ovog romana 
vraća kući. Posle Breakfast of Champions sledi roman Slapstick u kome se Traut ne pojavljuje (možemo pretpostaviti da se za to vreme bavio pisanjem prvog romana koji će biti regularno izdat ${ }^{51}$ ), ali se vraća već u sledeći, Jailbird $^{52}$, kao Bob Fender, pisac naučne fantastike, koji piše pod pseudonimom Kilgor Traut. ${ }^{53}$ Ovaj Trautov povratak možemo tumačiti na razne načine, jedan od kojih može biti kao njegov povratak u fikciju nakon što je bio pušten u realni svet, jer jednostavno spoljašnji, tj. svet izvan fikcije, ne postoji. Samo Trautovo ime (eng. trout - u prevodu pastrmka) nagoveštava da je njega nemoguće u potpunosti kontrolisati. (Greer, 1989: 321, 325) Vonegatov fiktivni alter ego mora ostati u fikciji, ako Vonegat želi da ostane u realnosti.

Patriša Vo govori o okviru teksta koji postavlja granice između sveta realnosti i sveta fikcije - da li je okvir nešto materijalno kao fizički početak i završetak romana ili je nešto više od toga? Autorka upoređuje modernističke tekstove sa metafikcijskim, koji su više postmodernistički - dok u modernizmu tekst počinje in medias res, metafikcijski romani počinju diskusijom o samim počecima i granicama. Savremena metafikcija stavlja akcenat na okvire, na to da je život jedino moguće gledati uz pomoć okvira za koje često ne znamo gde počinju, a gde se završavaju. (Waugh, 1996: 28-29) Većina Vonegatovih romana uokvirena je ramom metafikcije u cilju da pokažu da se do realnosti može doći samo kroz tekst. U romanu Cat's Cradle narator nam naglašava da ovo što on piše jeste knjiga o atomskoj bombi, i tako priči daje neku vrstu okvira. Breakfast of Champions se opire bilo kakvim ograničenjima jer su ona nametnuta ${ }^{54}$.

ne dokazuje da je Traut stvaran tako ni ime Kurt Vonegat na koricama romana Breakfast of Champions ne dokazuje da je Vonegat stvaran. Trautovo pojavljivanje u ulozi autora Venus on the Half-Shell izaziva konfuziju kod publike, tako da Farmer na sledećem izdanju mora da stavi svoj potpis i sliku na korice knjige, tako da roman više nije Trautovo delo. (Greer, 1989: 322-323)

51 Venus on the Half-Shell

52 Što je simbolično samo po sebi, jer je Traut upravo to, jedna zatvorska ptičica, koja može da pevuši samo unutar zidova fikcije.

53 "Yes-Kilgore Trout is back again. He could not make it on the outside. That is no disgrace" (Vonegat, 1981: ix)

54 "I had no respect whatsoever for the creative works [...] of Beatrice Keedsler [because she] had joined hands with other old-fashioned storytellers to make people believe that life had leading characters, minor characters, significant details, insignificant details, that it had lessons to be learned, tests to be passed, and a beginning, a middle, and an end." (Vonnegut, 2000: 209) 
Roman se završava samo onda kada pisac odluči da prestane da piše, pošto uvek ima još nešto da se kaže ${ }^{55}$. Čini se onda kontradiktorno to što ovaj roman ima predgovor i epilog, ako roman već ne može imati početak i kraj. Grir na to posmatra samo kao na produžetak ITD strukture (1989: 318), ali možemo na to gledati kao na još jedan način koji Vonegat pronalazi da parodira tehnike metafikcije.

$\mathrm{Na}$ osnovu niza postmodernističkih tehinka i ideja koje Vonegat koristi u svojoj prozi, ne preostaje nam ništa drugo nego da zaključimo da je on istinski postmodernista. Možemo ga nazvati i piscem metafikcije, kako to čini Patriša Vo. Sudeći po primerima koje smo prethodno naveli u ovom radu, nesumnjivo je da su Vonegatovi romani dijegetički metafikcionalni, po distinkciji koju pravi Linda Hačon, jer su svesni svojih procesa pripovedanja, ali se javljaju i u otvorenoj i prikrivenoj formi. Prikrivenu formu karakteriše metafikcija koja je prisutna na nivou strukture i nije očigledna, autorefleksivna je, ali ne mora biti samosvesna. Ovakav oblik metafikcije možemo primetiti u Vonegatovim romanima kao što su Cat's Cradle, Hocus-Pocus, Mother Night, Galapagos i Jailbird, u kojima metafikciju uočavamo upravo u strukturi teksta, jer u predgovorima ovih romana ili sistematično kroz tekst ukazuje se na okvir priče i na to u kom se odnosu prema tekstu nalazi Vonegat, kao autor, narator ili urednik. Ovi romani su češće autorefleksivni nego samosvesni - autorefleksiju prepoznajemo u onim segmentima gde narator pripoveda o svom pripovedanju, kao kada, na primer, narator romana Galapagos objašnjava zašto stavlja zvezdicu pored imena likova. Svi ovi romani nisu neophodno i samosvesni zato što ne potvrđuju da su svesni svoje fikcionalnosti. U romanima Breakfast of Champions i Slaughterhouse-Five metafikcija je očigledna i prepoznaje se na raznim nivoima, od strukture do komentara na račun pripovedanja. Metafikcija u ovim romanima jeste u otvorenoj formi, koja je i autorefleksivna i samosvesna i goni čitaoca da što pre postane svestan svoje aktivne uloge u stvaranju značenja teksta. Vonegat u ova dva romana obilato $\mathrm{i}$ stručno koristi tehnike metafikcije (mise-en-abîme, alegoriju, metaforu i

55 "The proper ending for any story about people it seems to me, since life is now a polymer in which the Earth is wrapped so tightly, should be ... ETC. And it is in order to acknowledge continuity of this polymer that I begin so many sentences with "And" and "So," and end so many paragraphs with " ... and so on." (Vonnegut, 2000: 228) 
defamilijarizaciju) da bi opisao proces stvaranja, ali i da bi davao primere i parodirao kako razne žarnove (kao što su naučna fantastika ili pornografija), tako i tehnike postmodernizma kao što je metafikcija. Vo smatra da svaki pisac metafikcije odgovara na dva problema u svojoj fikciji - na status samog književno-fikcionalnog diskursa u pogledu referencijalnosti, i status fikcionalnih likova koji u isto vreme i postoje i ne postoje (Waugh, 1996: 88-90). Vonegat se poigrava problemom referencijalnosti fikcionalnog teksta do te mere da ga dovodi do parodije, posebno u romanu Breakfast of Champions u kome nismo sigurni da li autor Kurt Vonegat piše ovu priču koja je fikcionalna dok sporadično ubacuje elemente iz sopstvene realnosti, ili je Kurt Vonegat narator unutar fikcionalnog sveta čiji ulazak u roman nije rušenje granica između realnog i fiktivnog, već određivanje nivoa fikcionalnosti unutar same fikcije. Status fikcionalnih likova u ovom romanu je takođe doveden u pitanje prvo sa Vonegatom, koji istovremeno i postoji i ne postoji, jer je ujedno i fiktivni lik i realna ličnost. Vonegat ovo dovodi do parodije onda kada njegovom literarnom alter-egu i glavnom liku romana, Kilgoru Trautu, podari slobodnu volju, i on izlazi sa stranica knjige u realni svet.

\section{Zaključak}

U romanu Slaughterhouse-Five su prisutni mnogi elementi koji su karakteristični za metafikciju: pomeranje granica između fiktivnog i realnog, komentarisanje samog romana i pripovedačkih tehnika upotrebljenih u njemu, problematika statusa likova, kao i Vonegatov povremeni prelazak iz realnog u fikcionalni svet. Čini se kao da je Vonegat ovde upotrebio metafikciju, tačnije istoriografsku metafikciju, sa iskrenom namerom da kroz samosvesni i autorefleksivni narativ pokaže strahote rata, ali ujedno i subjektivnost istorije. Naznake parodije metafikcije ne možemo primetiti u Vonegatovim naporima da napiše antiratnu knjigu. U romanu Breakfast of Champions prepoznajemo književnika koji je prevazišao prethodno korišćene tehnike. Metafikcija je i u ovom romanu izvanredno upotrebljena. Tehnika priče u priči je usavršena, sa Trautovim naučnofantastičnim romanima koji se pojavljuju tačno onda kada nam je potrebna kašičica vonegatskog seruma - alegorija na politiku, stanje društva, zagađenja 
životne sredine itd. Paradoks ulaska autora u tekst je akcentovan tačno toliko da istovremeno čitaocu prija i smeta. Defamilijarizacija se obilato koristi tako što se prosti pojmovi objašnjavaju i ilustruju kao za nekog ko nije sa ove planete. Nervozni predmeti, u obliku naučnofantastičnih priča, autobiografskih elemenata, pesmica, ilustracija itd. samo se gomilaju. Ono što nas goni da ovakvu vrstu fikcije nazovemo pre patafikcijom nego metafikcijom, jeste to što neke tehnike metafikcije Vonegat dovodi do apsurda. Razdvajanje autora od naratora postaje nemoguće, a još teže razlučivanje između autora i lika Vonegata onoga trenutka kada Vonegat odluči da uđe u tekst. On upravo želi da naglasi da i jeste nemoguće povući crtu između autora, naratora i određenih likova upravo zato što je to ogroman izazov za samog autora koji ih sve stvara. Pored toga što postaje lik u svojoj fikciji, on tvrdi da ne može u potpunosti da kontroliše svoje likove. Više puta ga postupci sopstvenih likova iznenade, kao kada Karabekian drži govor, kada šanker ima želju da izbaci Vonegata iz salona u kome se održava Festival umetnosti, ili kada Traut odbija da se odazove na Vonegatovo dozivanje na poslednjim stranama romana. Iskrena je borba između onoga što autor očekuje od svojih likova i onoga što oni moraju činiti. U trenucima kada Vonegata sopstveni likovi fizički povređuju zapažamo da fikcija odbacuje realnog autora, želi da ga se otarasi iako je ona samo kreacija nastala u njegovoj uobrazilji. Isto tako ni realnost ne može prihvatiti fiktivnog lika - Vonegat daruje Trauta slobodnom voljom da ode u svet i stvara, ali on se u realnom svetu ne može zadržati i vraća se u fikciju. Vonegat na taj način želi da parodira i dovede do ektremnih proporcija nestabilnost granice između fikcije i realnosti. Vonegat je svoj unutrašnji sukob (i nemogućnost razrešenja istog) između sebe kao autora i realne ličnosti, svog literarnog alter-ega i fikcionalnog Vonegata, kao i između svih ovih persona i likova u fikciji uspešno prikazao u romanu Breakfast of Champions. Vonegat ovde stručno primenjuje elemente metafikcije, tj. tehnike postmodernizma, a onda ih izlaže parodiji, baš kao pravi postmodernista. 


\section{Literatura}

Clancy, L. (1971). Running Experiments Off: An Interview. In Allen, W. R. (ed.). (1988).

Conversations with Kurt Vonnegut (pp. 46-56). Jackson and London: University Press of Mississippi.

Gibbs, A. (2014). Contemporary American Trauma Narratives. Edinburgh: Edinburgh University Press.

Greer, C. (1989). Kurt Vonnegut and the Character of Words. The Journal of Narrative Technique, Vol. 19, No. 3, 312-330. [on-line]. Dostupno preko: JSTOR. [25.05.2016.]

Hutcheon, L. (2014). Narcissistic Narrative: the Metafictional Paradox. Ontario: Wilfrid Laurier University Press.

King, S. (2011). 11.22.63. London: Hodder \& Stoughton.

McLaughlin, F. (1973). An Interview with Kurt Vonnegut, Jr. In Allen. W. R. (ed.). (1988). Conversations with Kurt Vonnegut (pp. 66-75). Jackson and London: University Press of Mississippi.

Nicol, B. (2009). The Cambridge Introduction to Postmodern Fiction. Cambridge: Cambridge University Press.

Tally Jr, R. T. (2009). A postmodern iconography: Vonnegut and the great American novel. In Boyle, E. \& Evans, A.(2009). Reading America: New Perspectives on the American Novel (pp. 163-178). Cambridge: Cambridge Scholars Publishing.

Vonnegut, K. (1980). How to write with style. IEEE Transactions on Professional Communication,Vol. PC-24. NO. 2. [on-line]. Dostupno preko: http://kmh-lanl.hansonhub.com/pc-24-66-vonnegut.pdf [27.05.2016]

Vonnegut, K. (1981). Zatvorska ptičica. Preveo sa engleskog Omer Lakomica. Zagreb: Znanje.

Vonnegut, K. (1994). Galapagos. London: Flamingo.

Vonnegut, K. (2000). Breakfast for Champions. New York: The Random House Group Limited.

Vonnegut, K. (2009). Mother Night: a novel. New York: Random House Publishing Group.

Vonnegut, K. (2010). Slapstick or Lonesome No More! New York: Random House Publishing Group. 
Vonnegutt, K. (2011). Klanica-PET ili dečji krstaški rat. Preveo sa engleskog Branko Vučićević. Beograd: Narodna Knjiga Alfa.

Vonnegut, K. (2013). Svračije noge. Preveo sa engleskog Goran Skrobonja. Beograd: Paladin.

Vonnegut, K. (2014). Hokus Pokus. Preveo sa engleskog Zoran Paunović. Beograd: Dereta.

Waugh, P. (1996). Metafiction: the Theory and Practice of Self-conscious Fiction. London and New York: Routledge.

Milica B. Abramović

\section{Summary}

\section{METAFICTION IN KURT VONNEGUT'S PROSE}

Metafiction, or fiction about fiction, according to Patricia Waugh, is a fictional text which is self-conscious of its status as fiction, and continuously draws reader's attention to that status and to the relationship between reality and fiction. Although metafiction can be detected in most experimental texts, this type of fiction became most popular in postmodernism. By comparing the principles of metafiction, the way they are defined by Patricia Waugh and Linda Hutcheon, with metafictional elements in Kurt Vonnegut's novels, the objective of this essay is to show the manner in which Vonnegut uses this technique in his fiction. Through literary analysis of the novel Breakfast of Champions it becomes obvious that Vonnegut bends metafiction and makes it absurd. Absolute confusion, which is the result of an attempt to determine who is Kurt Vonnegut in this novel (author, narrator, character or intruder), and Vonnegut's passing through the portal from reality into fiction (in which he cannot control his characters) indicate that Vonnegut surpasses the techniques of metafiction and intentionally parodies them.

Key words: Kurt Vonnegut, Breakfast of Champions, SlaughterhouseFive, metafiction, parody 